\title{
Effect of zinc on antibiotic susceptibility in standard escherichia coli
}

\begin{abstract}
An increasing problem for the treatment of different infectious diseases is bacterial resistance to antibiotics and other antimicrobial agents. Our hypothesis was that a correlation exists between metal tolerance and antibiotic resistance in bacteria. In the hospital the most common pathogen associated with various disease conditions is $E$. coli. So in the present study our test organism is standard E. coli strain 25922. It was exposed to varying concentrations of $\mathrm{Zinc}$ in the form of $\mathrm{ZnSO}_{4}$ ranging from $20 \mathrm{ppm}$ to $70 \mathrm{ppm}$. As the time period of contact with Zinc increased, the strain developed tolerance to increasing concentrations of Zinc. Important finding was that by time, the standard strain developed resistance to various classes of antibiotics in the presence of Zinc without even the presence of antibiotics themselves culture broth. The results indicate that metal contamination present in the environment may develop antibiotic resistance in otherwise antibiotic sensitive strains of bacteria when they are exposed to various metals such as Zinc in environmental surfaces. These bacteria when come in contact with humans or animals turn pathogenic and cause multiple drug resistant diseases. So there is a possible role of metals in spreading antibiotic resistance among bacteria.
\end{abstract}

Keywords: E. coli, antibiotic resistance, heavy metals, zinc, environment
Volume I Issue 2 - 2015

Tanveer Kaur, Satish Gupte, Mandeep Kaur Department of Microbiology, Gian Sagar Medical College \& Hospital, India

Correspondence: Dr. Satish Gupte, Department of Microbiology, Gian Sagar Medical College \& Hospital, Rajpura, India,Email drsatishgupte@hotmail.com

Received: July 14, 2015 | Published: September 10, 2015

\section{Introduction}

Heavy metal contamination is widespread in environment. Heavy metals cannot be degraded or destroyed because they are stable and act as persistent environmental contaminants. ${ }^{1}$ Heavy metals influence the microbial population by affecting growth resulting in decreased biomass as well as diversity. Therefore microbes have developed mechanisms to tolerate the metals through efflux, complexation, or reduction of metal ions or to use them as terminal electron acceptors in anaerobic respiration. ${ }^{2}$ Most mechanisms reported involve the efflux of metal ions outside the cell.

An increasing problem for the treatment of different infectious diseases is bacterial resistance to antibiotics and other antimicrobial agents. It is thought that a correlation exists between metal tolerance and antibiotic resistance in bacteria, ${ }^{3}$ because of the likelihood that resistance genes to both (antibiotics and heavy metals) may be located closely together on the same plasmid in bacteria. ${ }^{4,5}$ Thus we need to be more careful of the drastic use of antibiotics in medical practice, and also more aware of other antimicrobials, that we put into the environment, such as heavy metals. The volume of antibiotics used in hospitals and private households and released into effluent and municipal sewage indicates a selection pressure on bacteria. ${ }^{6}$ Heavy metal and pesticide releases into the environment are increasing continuously as a result of industrial activities and technological development, posing a significant threat to the environment because of their toxicity and persistence in nature. ${ }^{6}$ There is substantial overlap between known mechanisms for metals and antibiotic resistance, such as those for copper and tetracyclines, copper and ciprofloxacin, arsenic and $\beta$-lactam. ${ }^{7}$ Various studies have also pointed to strong patterns of co-occurrence between metal and antibiotic resistance in environmental settings. So in the present study, we have exposed the standard E. coli strain 25922 to increasing levels of $\mathrm{ZnSO}_{4}$ to see this co-occurrence of metal and antibiotic resistance.

\section{Materials and methods}

To study the role of metal (Zn) in different concerations on establishment, enhancement and reduction of antibiotic resistance among antibiotic susceptible standard E. coli strain, 25922

Preparation of $\mathrm{ZnSO}_{4}$ solution: Stock solution of $\mathrm{Zn}$ with the strength of 1000 ppm was prepared by dissolving $0.89 \mathrm{~g}$ of $\mathrm{ZnSO}_{4} \cdot 7 \mathrm{H}_{2} \mathrm{O}$ (NICE CHEMICALS) in $500 \mathrm{ml}$ double distilled water. Different concentrations of $\mathrm{Zn}$ were prepared from this stock solution by adding required volume of stock solution into peptone water. The conc. ranged from $10 \mathrm{ppm}$ to $100 \mathrm{ppm}$.

Preparation of standard inoculum of $E$. coli strain 25922 and exposing the strain to different concentration of $\mathrm{Zn}$ solution: Standard E. coli strain (ATCC 25922) was inoculated on MacConkey Agar (HIMEDIA). The colonies were passed into peptone water. After matching with 0.5 Macfarland standards, 3 loopfuls of culture broth were passed into different conc. of $\mathrm{Zn}$ ranging from $10 \mathrm{ppm}$ to $100 \mathrm{ppm}$ and incubated for 48 hours. After 48 hours, the inoculum was again subcultured into fresh peptone water containing similar $\mathrm{Zn}$ concentration to rule out any nutrition related mutations in the strain.

To check the viability and antibiotic susceptibility of test strain: The culture tubes were checked for turbidity and were plated on fresh MacConkey agar to check whether they were tolerant to that conc. of $\mathrm{Zn}$ or not. If colonies appeared, then Antibiotic susceptibility test of the test strains was performed by Kirby- Bauer Disk diffusion method on Mueller Hinton Agar (MHA) (HIMEDIA) twice a week. Antibiotic susceptibility pattern was noted every time to see the effect of $\mathrm{Zn}$ on induction of Antibiotic resistance in E. coli. 


\section{Results}

As seen in the Table 1, for the first 32days, the standard $E$. coli strain was unable to grow above $30 \mathrm{ppm}$ of $\mathrm{Zn}$ in peptone but subsequently it became tolerant to higher levels (40-50ppm) of $\mathrm{Zn}$ in 50days and to (60-70ppm) in about 60days. This data shows that the strain developed tolerance to increasing conc. of $\mathrm{Zn}$ by increasing time.

Table I Viability and tolerance of standard E. coli strain towards different concentrations of Zn. G, growth; NG, no growth

\begin{tabular}{lllll}
\hline Conc. of Zn (ppm) & \multicolumn{4}{c}{ Growth of E. coli in peptone water } \\
\cline { 2 - 5 } & Day 2 & Day 32 & Day 50 & Day 60 \\
\hline 20 & G & G & G & G \\
30 & NG & G & G & G \\
40 & NG & NG & G & G \\
50 & NG & NG & G & G \\
60 & NG & NG & G & G \\
70 & NG & NG & NG & G
\end{tabular}

The standard strain was tested for susceptibility to all antibiotics of Enterobacteracae during the period of study. As in the Table 2, it was susceptible to all antibiotics on the first day. Till $10^{\text {th }}$ day, it showed resistance to Cefuroxime and Ampicillin. After 50days it developed resistance towards ampicillin/ sulbactam. In about 60days it developed resistance towards Cefpodoxine and till 80days it developed resistance to Piperacillin, Ceftazidime and Clavulanat and Colistin as shown in Figure 1 and Figure 2.

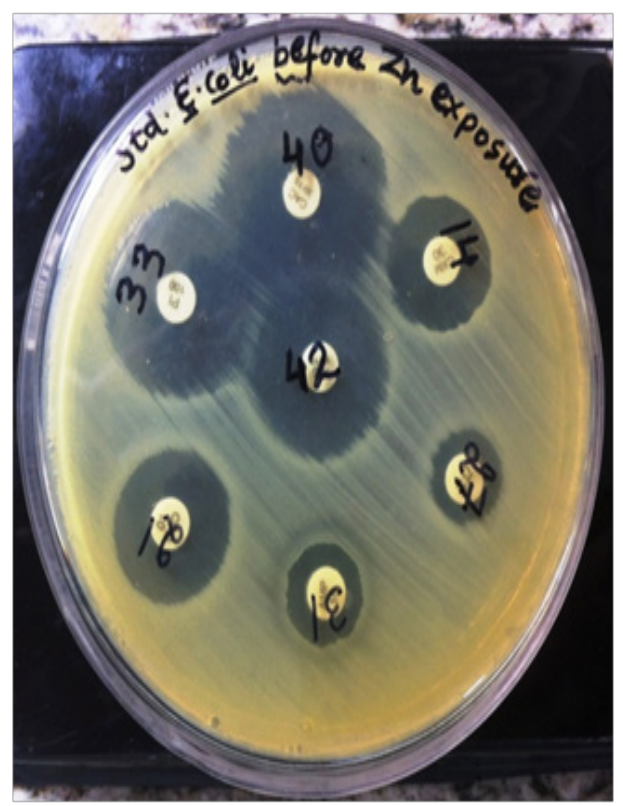

Figure I MHA plate showing AST pattern of Standard E. coli before Zn exposure.

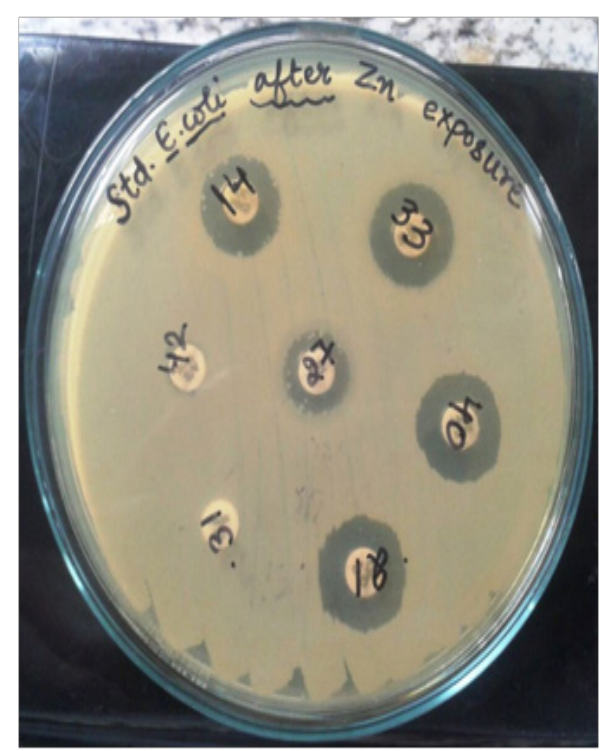

Figure 2 MHA plate showing AST pattern of Standard E. coli strain after Zn exposure till certain period of time.

Table 2 Effect of $\mathrm{Zn}$ on Antibiotic susceptibility pattern of standard E.coli. R, resistant; $S$, sensitive

\begin{tabular}{llllllll}
\hline $\begin{array}{l}\text { S. } \\
\text { no. }\end{array}$ & Antibiotics & $\begin{array}{l}\text { Day } \\
\mathbf{2}\end{array}$ & $\begin{array}{l}\text { Day } \\
\mathbf{1 0}\end{array}$ & $\begin{array}{l}\text { Day } \\
\mathbf{5 0}\end{array}$ & $\begin{array}{l}\text { Day } \\
\mathbf{6 0}\end{array}$ & $\begin{array}{l}\text { Day } \\
\mathbf{8 0}\end{array}$ & $\begin{array}{l}\text { Day } \\
\mathbf{9 5}\end{array}$ \\
\hline $\mathrm{I}$ & Cefuroxime & $\mathrm{S}$ & $\mathrm{R}$ & $\mathrm{R}$ & $\mathrm{R}$ & $\mathrm{R}$ & $\mathrm{R}$ \\
2 & Ampicillin & $\mathrm{S}$ & $\mathrm{R}$ & $\mathrm{R}$ & $\mathrm{R}$ & $\mathrm{R}$ & $\mathrm{R}$ \\
3 & $\begin{array}{l}\text { Piperacillin } \\
\text { S }\end{array}$ & $\mathrm{S}$ & $\mathrm{S}$ & $\mathrm{S}$ & $\mathrm{S}$ & $\mathrm{R}$ & $\mathrm{R}$ \\
4 & $\begin{array}{l}\text { Ampicillin/ } \\
\text { Sulbactum }\end{array}$ & $\mathrm{S}$ & $\mathrm{S}$ & $\mathrm{R}$ & $\mathrm{R}$ & $\mathrm{R}$ & $\mathrm{R}$ \\
5 & $\begin{array}{l}\text { Colistin } \\
6\end{array}$ & $\mathrm{~S}$ & $\mathrm{~S}$ & $\mathrm{~S}$ & $\mathrm{~S}$ & $\mathrm{R}$ & $\mathrm{R}$ \\
7 & $\begin{array}{l}\text { Cefpodoxine } \\
\text { Ceftazidime }\end{array}$ & $\mathrm{S}$ & $\mathrm{S}$ & $\mathrm{S}$ & $\mathrm{R}$ & $\mathrm{R}$ & $\mathrm{R}$ \\
& $\begin{array}{l}\text { and } \\
\text { Clavulanate }\end{array}$ & $\mathrm{S}$ & $\mathrm{S}$ & $\mathrm{S}$ & $\mathrm{S}$ & $\mathrm{S}$ & $\mathrm{R}$ \\
\hline
\end{tabular}

\section{Discussion}

Antibiotic resistance is a resistance of microorganisms to an antibiotic to which it was originally sensitive. The use of antibiotics and spread of antibiotic resistance in clinical settings is a well recognized problem, but antibiotics and antibiotic resistance as environmental problems and pollutants have largely been over looked. As a result, the increasing incidence of resistance to a wide range of antibiotic agents by a variety of organisms is a major concern facing modern medicine. ${ }^{8}$ We have done this innovative study by exposing standard E. coli to $\mathrm{ZnSO}_{4}$ to see changes in antibiotic resistance pattern. In a lab scale Zinc fed wastewater bioreactor studies, Peltier et al., ${ }^{9}$ concluded that sub toxic levels of zinc can cause increased antibiotic resistance in wastewater microbial communities at comparatively low antibiotic levels probably due to developed cross resistance resulting from preexposure to zinc. The results presented here show that pre- and/or co-exposure to $\mathrm{Zn}$ at sub-toxic levels can result in increased incidence of resistance to tylosin, oxytetracycline and ciprofloxacin among culturable bacterial populations in wastewater treatment reactors when those antibiotics are also present in the water. ${ }^{9}$ Resende et al., ${ }^{10}$ 
evaluated medically relevant bacteria in an aquaculture system and their susceptibility to antibiotics and toxic metals. The significant positive correlations were found between some antibiotic resistance genes and typical heavy metals such as $\mathrm{Cu}, \mathrm{Zn}$ and $\mathrm{Hg} .{ }^{10}$ In our present study, the data indicates that the Standard E. coli strain developed tolerance to increasing conc. of $\mathrm{Zn}$ by time and subsequently also developed resistance to many antibiotics in the presence of $\mathrm{Zn}$, without even the exposure of antibiotic itself. The colony morphology of $E$. coli also changed a little bit as it formed very minute colonies after about 45 days of exposure to Zinc. So it shows that metal ions such as $\mathrm{Zn}$ can also be responsible for antibiotic resistance in microorganisms converting them into pathogens.

In a developing country like ours, pollution is quite heavy due to increased concentration of metals like $\mathrm{Zn}, \mathrm{Cu}$ especially in view of our findings where increased Zinc level has repeated increase in multiple resistance against various antibiotics. Decreasing the contents of Zinc in polluted water can combat the antibiotic resistance. The role of proteins in reversing antibiotic resistance due to Zinc specifically, as scanned with the literature is not mentioned. But Aspergillomarasmine A is an polyamino acid naturally produced by the mold Aspergillus versicolor has been reported to inhibit two antibiotic resistance carbapenemase proteins in bacteria, New Delhi metallo-beta-lactamase 1 (NDM-1) and Verona integron-encoded metallo-beta-lactamase (VIM-2), and make those antibiotic-resistant bacteria susceptible to antibiotics. ${ }^{11}$

\section{Conclusion}

Heavy metal releases into the environment are increasing continuously as a result of industrial activities which continue persistence in the environment. Various studies along with our present study have also pointed to strong patterns of co-occurrence between metal and antibiotic resistance in environmental settings. Microorganisms when come in contact with these settings for some time develop metal tolerance and antibiotic resistance among themselves. These pathogens somehow when passed to humans, cause diseases and are difficult to treat due to developed antibiotic resistance. So, metal contamination and persistence in the environment should not be overlooked as it may be responsible for spreading antibiotic resistance among bacteria.

\section{Acknowledgements}

None.

\section{Conflict of interest}

The author declares no conflict of interest.

\section{References}

1. Gochfeld M. Cases of mercury exposure, bioavailability and absorption. Ecotoxicol Environ Saf. 2003;56(1):174-179.

2. Ehrlich HL, Brierley CL. Microbial mineral recovery. USA: McGrawHill; 1990. p. 249-275.

3. Enne VI, Livermore DM, Stephens P, et al. Persistence of sulphonamide resistance in Escherichia coli in the UK despite national prescribing restriction. Lancet. 2001;357(9265):1325-1328.

4. Smith JJ, Howington JP. Plasmid maintenance and expression in Escherichia coli exposed to the Antarctic marine environment. Antarctic Journal of the United States. 1993;28(5):123-124.

5. Rasmussen LD, Sørensen SJ. The effect of longterm exposure to mercury on the bacterial community in marine sediment. Curr Microbiol. 1998;36(5):291-297

6. Durve A, Naphade S, Bhot M, et al. Characterization of metal and xenobiotic resistance in bacteria isolated from textile effluent. Advances in Applied Science Research. 2012;3(5):2801-2806.

7. Chudobova D, Dostalova S, Blazkova I, et al. Effect of ampicillin, streptomycin, penicillin and tetracycline on metal resistant and non resistant Staphylococcus aureus. Int J Environ Res Public Health. 2014;11(3):3233-3255.

8. Moges F, Endris M, Belyhun Y, et al. Isolation and characterization of multiple drug resistant bacterial pathogens from waste water in hospital and non hospital environments, Northwest Ethiopia. BMC Res Notes. 2014;7:215

9. Peltier E, Vincent J, Finn C, et al. Zinc induced antibiotic resistance in activated sludge bioreactors. Water Res. 2010;44(13):3829-3836.

10. Resende JA, Silva VL, Fontes CO, et al. Multidrug-resistance and toxic metal tolerance of medically important bacteria isolated from an aquaculture system. Microbes Environ. 2012;27(4):449-455.

11. King AM, Reid-Yu SA, Wang W, et al. Aspergillomarasmine A overcomes metallo- $\beta$-lactamase antibiotic resistance. Nature. 2014;510(7506):503-506. 